\title{
Notice of Redundant Publication
}

\author{
Seth S. Leopold MD
}

Published online: 3 July 2013

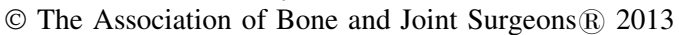

After publishing the paper, "3-D CT is the Most Reliable Imaging Modality When Quantifying Glenoid Bone Loss" by Bishop et al. [1], it was brought to our journal's attention that the article contained substantial redundancies with an earlier published article in the Journal of Shoulder and Elbow Surgery entitled, "Comparison of Various Imaging Techniques to Quantify Glenoid Bone Loss in Shoulder Instability" by Rerko et al. [2]

The later article, by Bishop et al. [1], neither mentioned nor referenced the earlier published work.

The author certifies that he, or any members of his immediate family, has no commercial associations (eg, consultancies, stock ownership, equity interest, patent/licensing arrangements, etc) that might pose a conflict of interest in connection with the submitted article.

All ICMJE Conflict of Interest Forms for authors and Clinical

Orthopaedics and Related Research ${ }^{\circledR}$ editors and board members are on file with the publication and can be viewed on request.

This is a notice of redundant publication to the original article available at doi:10.1007/s11999-012-2607-x.

S. S. Leopold $(\bowtie)$

Clinical Orthopaedics and Related Research, 1600 Spruce Street,

Philadelphia, PA 19103, USA

e-mail: sleopold@clinorthop.org

\section{References}

1. Bishop JY, Jones GL, Rerko MA, Donaldson C, MOON Shoulder Group. 3-D CT is the most reliable imaging modality when quantifying glenoid bone loss. Clin Orthop Relat Res. 2013;471: 1251-1256.

2. Rerko MA, Pan X, Donaldson C, Jones GL, Bishop JY. Comparison of various imaging techniques to quantify bone loss in shoulder instability. J Shoulder Elbow Surg. 2013;22:528-534. 